\title{
Best Practice Approach For A National Road Safety Strategy
}

\author{
Khair Jadaan ${ }^{1}$, Ethar Braizat ${ }^{2}$
}

\begin{abstract}
The magnitude of the road safety problem in developing countries requires the researchers and decision makers to provide approaches to reduce the overall number and severity of accidents. However, the implementation of road safety measures bears a lot on the various stakeholders with multitude of interests leading to the development of what is termed "Best Practice" strategy for road safety.

This paper explains the concept of Best Practice (BP)and provides an appraisal of the road safety situation in Jordan as a case study of developing countries. The BP approach is then used to identify the most promising sets of investments under Jordanian roadway and traffic conditions. The assessment process is facilitated through using some developed selection and ranking measures.

The details of a comprehensive road safety strategy that aim to improve road safety on the road network is outlined.
\end{abstract}

Keywords — Road safety, Best practice, Jordan, Strategy.

\section{INTRODUCTION}

All counties suffer from the road accident problem. Yet the size of the problem is different from one country to another, because countries vary widely in their development levels, road safety systems and experiences. According to Jacobs et al.(1), the majority of road deaths and injuries occur mostly in developing countries.

While developed countries have in general succeeded in checking and even reversing the annual number of road accident fatalities, the number of fatalities in developing countries have significantly increased, and will, following current trends, continue to increase with growing motorization if no effective remedial actions are taken. A recent report shows that 68 countries have seen a rise in the number of road traffic deaths since 2010, of which $84 \%$ are lower middleincome countries(2).

The main reasons for the poor safety record in developing countries are(3):

Lack of awareness of the road safety problem in the public, the political and the professional arenas;

Lack of institutional capacity and of adequately trained and motivated staff; and

Insufficient funding of road safety measures.

The number of road traffic deaths has plateaued since 2007.The plateau in road traffic deaths, set against a $4 \%$ increase in global population and $16 \%$ increase in motorization, suggests that road safety efforts over the past 3

\footnotetext{
${ }^{1}$ Professor, Civil Engineering Department, University of Jordan

${ }^{2}$ Civil Engineer, Development Consulting Consortium, Amman, Jordan
}

years have saved lives (2). Low- and middle-income countries, however, still bear a disproportionate burden of road traffic deaths where the rates are more than double those in highincome countries ( Table I)

TABLE 1: Vehicles, Population, AND Fatalities AmONG High Income, MIDDLE INCOME AND LOW INCOME COUNTRIES

\begin{tabular}{llll}
\hline \hline Channels & $\begin{array}{l}\text { Low } \\
\text { Income }\end{array}$ & $\begin{array}{l}\text { Middle } \\
\text { Income }\end{array}$ & $\begin{array}{l}\text { High } \\
\text { Income }\end{array}$ \\
\hline $\begin{array}{l}\text { Population } \\
\text { Registered }\end{array}$ & 12 & 70 & 18 \\
$\begin{array}{l}\text { Vehicles } \\
\text { Fatalities }\end{array}$ & 1 & 53 & 46 \\
$\begin{array}{l}\text { Fatality } \\
\begin{array}{l}\text { Rate(/100,000 } \\
\text { population) }\end{array}\end{array}$ & 16 & 74 & 10 \\
\hline
\end{tabular}

The magnitude of the problem in developing countries including Jordan, its rates of growth and the associated economical and social impacts are alarming, which calls the need for a comprehensive strategy to improve the road safety in Jordan. However, the implementation of road safety measures bears a lot on the various stakeholders with multitude of interests leading to the development of what is termed "Best Practice" strategy for road safety.

\section{II.Definition Of "Best Practice" And "Best Practice GUIDELINES"}

There is no commonly agreed definition of "Best Practice" but it obviously refers to a road safety policy that has proven to be successful meaning brings about a sustainable reduction in the number of road accidents and in particular the number of resulting casualties.

The term "Best Practice Guidelines" for road safety engineering refers to guidelines intended to help highway agencies implement effective safety management of the road system for which they are responsible (5). The literature $(6,7)$ covered aspects of this complex topic dealing with low cost road and traffic engineering measures and with road safety audits and safety impact assessment. This work is mainly based on the previous research in the area, but adds some new material.

\section{Selection Criteria For Best Practice Measures}

The best practice candidates are identified and described based on the following criteria(4): 
- Focus of the measure: a clear definition of the road safety problem to be solved and precise idea of how the measure will affect this problem.

- Magnitude of the road safety problem

- Expected effects on safety which addresses the process of implementation.

- Evaluation of effects on road safety based on accident statistics

- Costs and benefits analysis

- Acceptance by public and policy makers

- Sustainability over time

- Transferability: using the measure successfully on a larger scale (regional/national level).

It is realized that many road safety measures cannot respond to these eight criteria in numerical terms and with hard facts, because evidence-based effects or evaluation studies are rare.

The eight selection criteria proved to be quite restrictive and demanding. Therefore, a distinction between best, good and promising practices was recommendable as follows:

In order to be labeled as Best Practice, a measure should comply with most of the selection criteria. In particular its effectiveness in terms of expected reduction of road crashes, deaths and serious injuries should have been demonstrated in previous scientific evaluation work;

Good Practice measures fit in with most of the criteria, but suffer from a lack of data in the criteria 'scientific evaluation of the effects' and/or 'cost benefit ratio';

Promising Practices are mainly "new" measures that have not yet been subject to a full-fledged evaluation but, according to expert opinion, have a high potential of improving road safety .

\section{RoAd SAFETy BeSt PRACTICE GUIDELINES}

The essential elements of a systematic approach to road safety engineering are outlined in the following steps (5):

Step 1: Define suitable elements of the road system such as road sections of a given length, junctions, horizontal curves, bridges, and tunnels.

Step 2: Analyze distribution of accidents for each type of element with respect to the mean number of accidents and the variance.

Step 3: Identify the safety performance function in each set of elements. A safety performance function is an equation that describes the sources of systematic variation in accidents, fitted by means of appropriate multivariate analysis.

Step 4: Estimate safety for each element using the empirical Bayes method which combines information from two clues to safety, and can be used to estimate the expected number of accidents for each element.

Step 5: Define the abnormally high accident locations and identify them statistically

As a first step it is necessary to define the elements of the road system that are suitable for safety analysis. These elements may include road sections of various types of roads, junctions, curves, bridges or tunnels. It is important that the elements of the road system are identically defined and can be counted.

\section{V.APPRAISAL OF ROAD SAFETY IN JORDAN}

The lack of reliable data besides the problem of underreporting constitute a serious challenge to researchers in developing countries including Jordan. Accident statistics of Jordan show that current traffic safety conditions are already extremely serious. The number of accidents has increased more than five-fold between 1995 and 2013 with an estimated cost of JOD 336 (US\$ 500) million. The situation will undoubtedly worsen in the near future, in face of the rapid increase in the use of motorized means, within a travelling and social environments that are not prepared to experience such changes. A number of studies investigated the magnitude of the problem, its rates of growth and the associated economical and social impacts $(8,9)$ while other studies focused on the prediction of future number and severity of accidents $(10,11,12)$.

A more recent study (13) carried the matter further producing a thorough investigation into the prediction, cost and strategy issues of the problem. Based on the most reliable available national statistics,

Three fatality rate trends are analyzed; the number of fatalities per 1000 accidents, per 10,000 vehicles and per 100,000 population. Beside other economical, demographic and social factors, the trends shown in Table II may give an indication of the overall effectiveness of the road safety programs and activities implemented in Jordan over the past years. Accident prediction models developed for Jordan revealed that the situation will further deteriorate in the future unless appropriate countermeasures are implemented.

Studying the factors contributing to accident occurrence in Jordan showed that road users contributed to $94.74 \%$ of total reported accidents, whereas road failures and vehicle defects contributed to $4.46 \%$ and $0.81 \%$ respectively. The most common driver errors are following too closely $10.6 \%$, not giving priorities to pedestrians $10.18 \%$ and not giving priorities to vehicles $6.33 \%$. The most common pedestrian failures are crossing from a wrong place $7.46 \%$, walking on the road $2.15 \%$, crossing in front of a parked vehicle $1.08 \%$ and other factors $2.94 \%$. Road defects contributed to accident occurrence are either holes and/or humps on roads $1.56 \%$, defects in pavement $0.80 \%$, maintenance/works $0.60 \%$ and water on road surface $0.36 \%$. Furthermore, most of vehicle defects at the time of accidents are brakes defects $0.36 \%$, tires defects $0.29 \%$, windscreen wipers and steering defects $0.16 \%$. Meanwhile, only about $20 \%$ of all drivers in Jordan use the seatbelt. The highest rates of using the seatbelt were observed among female drivers of private cars and taxi drivers and the lowest rates were among police drivers and army cars. 
TABLE II TRENDS OF TRAFFiC ACCIDENTS RELATED STATISTICS DURING THE PERIOD (2003-2012)

\begin{tabular}{|c|c|c|c|c|c|c|c|c|c|c|}
\hline & 2003 & 2004 & 2005 & 2006 & 2007 & 2008 & 2009 & 2010 & 2011 & 2012 \\
\hline $\begin{array}{l}\text { Fatalities/1000 } \\
\text { accidents }\end{array}$ & 13.4 & 11.6 & 9.5 & 9.1 & 8.9 & 7.3 & 5.5 & 4.8 & 4.9 & 7.2 \\
\hline $\begin{array}{l}\text { Injuries/1000 } \\
\text { accidents }\end{array}$ & 295.7 & 238 & 211.5 & 183.7 & 162.4 & 137.7 & 127.5 & 124.3 & 127.1 & 151.9 \\
\hline Fatality Index * & 0.043 & 0.046 & 0.043 & 0.047 & 0.052 & 0.05 & 0.041 & 0.037 & 0.037 & 0.045 \\
\hline $\begin{array}{l}\text { Fatality/10,000 } \\
\text { vehicles }\end{array}$ & 14.6 & 13.4 & 11.6 & 11.9 & 11.8 & 8.2 & 6.8 & 6.2 & 6.0 & 6.7 \\
\hline $\begin{array}{ll}\text { Injury } & / 10,000 \\
\text { vehicle } & \end{array}$ & 321.4 & 272.2 & 258.6 & 238.5 & 213.4 & 153.6 & 157.1 & 161.8 & 158.0 & 141.2 \\
\hline $\begin{array}{l}\text { Fatality/ } \\
100,000 \\
\text { populations }\end{array}$ & 15.2 & 15.3 & 14.4 & 16.1 & 17.3 & 12.6 & 11.3 & 11.0 & 11.1 & 12.8 \\
\hline $\begin{array}{l}\text { Injury } / 100,000 \\
\text { populations }\end{array}$ & 335.2 & 312.6 & 321.2 & 321.8 & 314.0 & 237.8 & 261.9 & 284.7 & 290 & 268.4 \\
\hline Severity Rate $* *$ & 0.31 & 0.25 & 0.22 & 0.19 & 0.17 & 0.14 & 0.13 & 0.13 & 0.13 & 0.162 \\
\hline
\end{tabular}

*Fatality Index = No. of Fatalities/No. of Casualties

** Severity Index $=$ No. of Casualties/No. of Accidents

fields to cover, the set of categories chosen included:

- Education and campaigns

\section{IDENTIFYING BEST PRACTICES FOR JORDAN}

The results of road safety analysis in Jordan presented in Section 6 requires the researchers and decision makers to devise a robust strategy to improve the road safety situation. It is of prime importance to note that the implementation of road safety measures bears a lot on the various stakeholders with multitude of interests leading to the development of what is termed "Best Practice" strategy for road safety.

\subsection{Methodology}

The aim of this study is to develop best practice for road safety in Jordan by considering different topics, various approaches and a huge variety of implementation scenarios for being included in one comprehensive strategy. The process to develop the best practice is by reviewing different strategies and approaches that were developed in a various countries.

The first phase of the study involved selection of a number of best practice measures that are considered relevant to improve future traffic safety in Jordan. As a starting point, a set of instruments was prepared (14):

- A list of road safety measures in order to select the best practice measures;

- A decision upon the selection criteria for the best practices which was the acceptance of drivers population to these practices.

- a questionnaire for data collection in order to provide an insight into these issues with the aim of evaluating how effective road users thought the best practice measures would be in reducing the number of accidents (effectiveness index on a 0-5 scale), and also how much they would be in favor of the measure if actually being introduced (favourability index on a $0-5$ scale).

For the purpose of this study, given the range of road safety
- Driver training, testing and licensing

- Vehicles

- Infrastructure

- Enforcement

- Institutional organization of road safety

In order to be labeled as Best Practice, a measure should comply with most of the selection criteria. In particular its effectiveness in terms of expected reduction of road crashes, deaths and serious injuries should have been demonstrated in previous scientific work

The questionnaire was distributed to collect information on what representative sample of road users with different income and educational level thought about a variety of possible best practice measures

In total, 39 Best Practice nominations were chosen, taking the above six selection criteria into account. . The measures were considered to reduce road traffic accidents and were devised to gauge how well the public might accept and favor them as countermeasures (CMs), and how effective these measures were as perceived by road users.

\subsection{Results}

The questionnaire was analyzed and the effectiveness and favorability indices were computed where each index represents the arithmetic mean of all the rating responses from 1 to 5 with the higher indices given lower ranking number. The effectiveness and favorability indices were combined for each remedial measure, giving equal weight for each index, in order to rank the measures in terms of the merging between effectiveness and favorability. The results are shown in Table III which gives a listing of the highest ten measures thereby enabling the identification of those interventions with the highest potential for improving road safety in Jordan. 
TABLE III: THE HigheSt EFFECTIVE AND FAVORABLE INTERVENTIONS

\begin{tabular}{lll}
\hline \hline Remedial Measure & $\begin{array}{l}\text { Effectiveness and } \\
\text { Favorability Index }\end{array}$ & Rank \\
\hline $\begin{array}{l}\text { Control intensification on overspeed } \\
\text { violations on urban roads }\end{array}$ & 4.085 & 1 \\
$\begin{array}{l}\text { Control intensification on overspeed } \\
\text { violations on rural roads }\end{array}$ & 4.06 & 2 \\
$\begin{array}{l}\text { Decreasing the maximum speed limits } \\
\text { on urban roads }\end{array}$ & 4.015 & 3 \\
$\begin{array}{l}\text { Impose the use of reflecting triangle } \\
\begin{array}{l}\text { Placing of signs at high-accidents } \\
\text { locations }\end{array}\end{array}$ & 4.01 & 4 \\
$\begin{array}{l}\text { Increase traffic education in schools } \\
\text { Using automatic jail penalty on drunk } \\
\text { drivers causing accidents }\end{array}$ & 3.965 & 5 \\
$\begin{array}{l}\text { Increase the number of play parks and } \\
\text { recreational areas }\end{array}$ & 3.88 & 6 \\
$\begin{array}{l}\text { Removing the obstacles from medians } \\
\text { that restricts sight distance }\end{array}$ & 3.88 & 7 \\
$\begin{array}{l}\text { Providing safe sidewalks for } \\
\text { pedestrians free of obstacles }\end{array}$ & 3.875 & 9 \\
\hline \hline
\end{tabular}

It is noticed from the results that the measures which gain both high effectiveness and favourability are those which are related to speeding either on urban or rural roads. This indicates that there is a feeling among Jordanian drivers of poor driver behavior and low observance to traffic rules and regulations. In view of the high number of offences, this may also indicate low speed harmonization level between design, operating and posted speeds. The identified measures may be regarded as short - term remedies which have the potential to produce significant reduction in the frequency and severity of accidents on Jordan's road network.

\section{FORMULATION OF ROAD SAFETY STRATEGY FOR JORDAN}

The results of road safety analysis in Jordan presented in Section 3 requires the researchers and decision makers to devise a robust strategy to improve the road safety situation. It is of prime importance to note that the implementation of road safety measures bears a lot on the various stakeholders with multitude of interests leading to the development of what is termed "Best Practice" strategy for road safety.

Core to the Road Safety Strategy is a framework of best practices. The framework consists of a multi-cell matrix of key target groups and contributing factors, along with a variety of road safety initiatives that jurisdictions may adopt to address their specific priorities.

Jurisdictions will have the flexibility to adopt specific strategies depending on their suitability, feasibility (i.e.: resources) and acceptability (i.e.: operating environment). The framework of best practices is intended to be fluid, meaning that new target groups, contributing factors and suggested initiatives and strategies can be added to the Road Safety Strategy over time. The components that are essential for the formulation and successful implementation of the strategy include vision, objectives, targets, action plan, evaluation and monitoring; research and development, quantitative modelling, institutional framework, and funding [Details of the strategy, outlined earlier, are as follows (14):

\subsection{The Vision and Objectives}

A clear vision is to have the "safest roads in the world" so that no person should be killed or seriously injured on Jordan's roads. In order to achieve this ultimate vision the Jordanian Government must set reduction factors that suit Jordan, support this vision and focus its road safety efforts on contributing towards achieving this vision.

The main objective of the strategy is reducing the number and severity of traffic accidents on Jordan's road network. The strategic objectives are expected to result in safer road users, safer road infrastructure and safer vehicles through:

1. raising public awareness and commitment to road safety,

2. improving communication, cooperation and collaboration among all stakeholders,

3. enhancing enforcement,

4. improving road safety information in support of research and evaluation.

To place the vision of having the safest roads in context, the vision would result in Jordan achieving a rate of 6.4 fatalities per 100,000 population. In 2012 , there were 816 fatalities, which translate to a comparable fatality rate of 12.8 per 100,000 populations. For Jordan to achieve a target of 408 fatalities or less per 100,000 populations would have required a further reduction of 408 fatalities in 2012.

In their efforts to help achieve the objectives of the vision, the enforcement community, for example, should change its traffic services delivery model from a random patrol enforcement strategy to a team service delivery model where data analysis is combined with education and enforcement strategies to address key causal factors through targeted enforcement.

\subsection{Key Guiding Principles}

The development of the Strategy is based on four key guiding principles, including:

1. downward trends in fatalities and serious injuries over the years,

2. safer systems concepts,

3. a five-year timeframe,

4. a framework of best practices.

\section{Downward Trends}

The successes in achieving a directional downward trends in the rate-based number of fatalities and serious injuries will be the principle against which the strategy will be measured at the national level on a yearly basis, rather than the actual fatalities and serious injuries.

Two rate-based indicators are commonly used internationally: fatalities(or serious injuries) per million populations; and fatalities (or serious injuries) per billion kilometers travelled. However, in view of the fact that no data are available on the second measure, then only the first measure (fatalities/million population) will be used.

\section{Safer Systems Concept}

This "safer systems concept" is an effective mean to bring all stakeholders together by recognizing the interdependencies that exist between these elements. It incorporates "safer systems concepts" rather than a "safe systems approach", which traditionally involves very significant long-term 
investments.

\section{Five-Year Timeframe}

The term for the Road Safety Strategy is five years rather than ten years and could be renewed or extended. A shorter timeframe will help build and maintain momentum for jurisdictional initiatives throughout the life of the Road Safety Strategy.

Jurisdictions will continue to report fatalities and serious injuries to Traffic Department on an annual basis and these data will be used to produce a report on national progress in reducing fatalities and serious injuries using rate-based indicators.

\section{The Framework of Best Practices}

A Framework of best practices is core to the Road Safety Strategy. The framework consists of a multi-cell matrix of key target groups and contributing factors, along with a variety of road safety initiatives that jurisdictions may adopt to address their specific priorities.

The framework is intended to enable new target groups, contributing factors and suggested initiatives and strategies to be added to the Strategy over time as need arises.

\subsection{Key Target Groups}

The key groups of driver being targeted are defined as follows:

- Young drivers: Drivers under the age of 21 years.

- Vulnerable road users: Pedestrians, motorcyclists and cyclists and persons in personal mobilized devices such as scooters.

- Commercial carriers: A person or entity who is responsible for the operation of a commercial vehicle.

- High-risk drivers: Repeat offenders with patterned illegal driving behaviors such as recurring incidences of traffic violations. The medically-at-risk-drivers may also be targeted within this category. Those are the drivers whose existing medical condition (e.g.: epilepsy, ischemic heart disease etc.) may affect their safe vehicle operation, the safety of their occupants and the safety of other road users. This includes agingrelated driver performance considered beyond normal driving.

- General population: Road users who benefit from making roads, vehicles and road users safer through introducing the interventions.

\subsection{Key Target Contributing Factors}

The key causes of collisions being targeted are defined as follows:

- Aggressive Driving: Includes driving too fast for road conditions, driving at speeds beyond posted legal limits on all road types, and driver behaviors that put other road users at risk of crashes and injuries.

- Impaired Driving: Includes all forms of impairment, such as impairment resulting from fatigue, distracted behaviors or the ingestion of a substance such as alcohol

- Occupant Protection: Includes issues pertaining to proper restraint use among all road users, vehicle technology enhancements (crashworthiness and crash avoidance) and safer roads (e.g.: dangerous roadside obstacles, lighting, etc.).

- Environmental Factors: Includes all factors that may increase the risk of crash occurrence such as roadway construction, road surface condition, and weather conditions.

For each target group and contributing factor there may be more than one intervention or strategy. A range of strategies is recommended to address road safety issues which may include education and training, communication and awareness, enforcement, Information/data/research, Policy, legislation and regulation, technologies aimed at helping drivers to avoid collisions, road infrastructure improvements and establishment of linkages between jurisdictional, national or international governmental and non-governmental organizations with a vested interest in road safety.

\section{VIII.CONCLUSION}

This research on best practices related to road safety illustrated the concept of best practice worldwide, which is essential as it may assist to better understand the way that road safety improvements have been and should be achieved.

Taking Jordan as a case study, an appraisal of the road safety situation was carried out and a number of road safety measures were presented and assessed in order to identify the most promising sets of investments under Jordanian roadway and traffic conditions. The assessment process was facilitated through using some developed selection and ranking measures namely favourabi[ity and effectiveness of the interventions.

Considering both the effectiveness and favorability indices for 39 nominated measures, the best practice measures were identified as being the most appropriate for implementation. A National Road Safety Strategy (NRSS) was developed and it's details presented.

The final output of this study provides all parties involved in traffic safety with a best practice guide and a comprehensive road safety strategy to assist them in their initial strategic choice of cost-effective investments that aim to improve road safety.

\section{ACKNOWLEDGMENT}

This work was prepared during the sabbatical year 2015 2016 granted to Prof. Jadaan by the University of Jordan.

\section{REFERENCES}

[1] Jacobs G, Aaron-Thomas A, Astrop A., (2000). Estimating global road fatalities. TRL Report 445. Transport Research Laboratory, 2000, London.

[2] Zietlow G,(2006). The road safety cent, management and financing of road safety in low-income countries, GTZ, Division 44, Environment and Infrastructure Sector.

[3] WHO, World Health Organisation, (2004). World report on road traffic injury prevention, Chapter 3 "Risk Factors", Geneva. http://www.who.int/world healthday/2004/infomaterials/world report

[4] Winkelbauer, M., and Machata,K., (2008), Best Practices For Road Safety in Europe: A Systematic Approach, Transport Research Arena Europe, Ljubljana

[5] Department for Transport, (2001), Road Safety Good Practice Guide, U.K. 
[6] Road Traffic Management Corporation, (2012),South African Road Safety Audit Manual Second Edition

[7] Yannis,G, Evgenikos, P. and Papadimitriou,E., (2008), Best practice for cost-effective road safety infrastructure investments, Conference of European Directors of Roads (CEDR)

[8] Jadaan K, Al-Hyari I, Naghawi H, Ammourah R, Al Nabulsi Z.(2013), Traffic safety in Jordan: magnitude, cost and potential countermeasures", Journal of Traffic and Logistics Engineering, 1 pp 54- 57. https://doi.org/10.12720/jtle.1.1.54-57

[9] Bener A, Hussain S, Al-Malki S, Shotor M, Jadaan K. (2010) Road traffic fatalities in Qatar, Jordan and the UAE: estimates using regression analysis and the relationship with economic growth, Eastern Mediterranean Health Journal (EMHJ) 15(3) pp 318-323.

[10] Jadaan K, Al-Fayyad M, Gammoh H. ( 2014) Prediction of road traffic accidents in Jordan using artificial neural network, Journal of Traffic and Logistics Engineering 2, pp 92-94.

https://doi.org/10.12720/jtle.2.2.92-94

[11] Al-Matawah J,Jadaan K. (2009)Applications of prediction techniques to road safety in developing countries, Int. J. Appl. Sci. Eng.(IJASE) 7(2) pp 169-175.

[12] Jadaan K, Foudeh L, Al- Marafi M,Msallam M. (2014) Modeling of accidents using safety performance function," in Proc. Int. Conf. on Agricultural, Environment and Biological Sciences. Antalya, Turkey, pp.104-108.

[13] Braizat E, Gammoh H, Al- Rafayah S,(2014). Classical and innovative road safety issues: prediction, cost , and strategies, Graduation Project, Dept. of Civil Eng., University of Jordan, Amman, Jordan.

[14] Jadaan k, Bener A, Braizat,E, (2016), Formulation of road safety strategy for developing countries with special reference to Jordan, Advances in Transportation Studies an international Journal Section B, pp. 101-111. 